\title{
Non-Equivalence of Antibiotic Generic Drugs and Risk for Intensive Care Patients
}

\author{
Kirkpatrick C $J^{1 *}$, Ramzan Rangoonwala ${ }^{1}$, Mykhaylo Reshetnykov ${ }^{1}$, Mike Barbeck ${ }^{1}$ and Shahram Ghanaati ${ }^{1,2}$ \\ ${ }^{1}$ Institute of Pathology, University Medical Center of the Johannes Gutenberg University, Mainz, Germany \\ ${ }^{2}$ Clinic for Maxillofacial and Plastic Surgery, Johann Wolfgang Goethe University, Frankfurt/Main, Germany
}

\section{Abstract}

Background: The underlying axiom in applying generic drugs is the equivalence of their active ingredient with the (usually more expensive) innovator product, an all-embracing statement with the insidious result that physicians assume that the generic products have been subjected to the same rigorous testing regimens as the brand-name products. The present paper presents novel experimental data on an investigator-blinded comparison between the innovator imipenem antibiotic, and a number of its generics.

Methods: Particulate matter contamination of each group was visualized by means of a membrane filter method. Functional studies in an animal model-the dorsal skinfold chamber technique in mice-designed to simulate the state of microcirculatory dysfunction in intensive care patients was performed, in order to assess the influence of the particulate matter of each group on the functional capillary density of the striated skin muscle, after their intravenous injection.

Results: The results showed massive particulate contamination of the generics, in a size range relevant for impacting the microcirculation. The particulate contamination contributed in some generic groups to a significant shutdown of tissue perfusion.

Conclusion: The presented data underscore the need to raise the regulatory barriers for the entry of generics to the market, well beyond the simplistic proof of "bioequivalence", which in no measure deals with the essential questions of quality and patient safety. If generics are used, they should be tested by a filter technique and optical microscopy, to ensure the absence especially of small particulate contaminants and their purity.

Keywords: Antibiotic generic drugs; Generic drugs

\section{Introduction}

Generic drugs are prevalent in current medical practice, and as a result of the prevailing economics of modern health care systems, they are being propagated as the medications of choice [1]. The usage of generic drugs is generally based upon the presumption that their active compounds are as efficacious as that of the innovator products, but cheaper and therefore desirable from an economic point of view [24]. For that reason, many countries have established the commitment to generic drugs (by laws and directives), as a chance to reduce the exploding costs of their healthcare systems [4-7]. The US government passed a law package, the US Drug Price Competition and Patent Restoration Act (Public Law 98-417, "Hatch-Waxman Act"), that opened the market for a high level of generic drug sales [8,9]. One enactment of this act includes the drug price competition section, in which the approval process for generic drugs that is regulated by the US Federal Drug Administration (FDA) was altered $[8,9]$. Thus, the FDA was directed to assess the approval of a generic drug by pharmaceutical equivalence and bioequivalence studies, as well as abbreviated new drug applications (ANDAs), that generally do not require preclinical and clinical data to establish safety and effectiveness $[9,10]$. Due to that the FDA applies the "plus-or-minus-twenty-percent test", by which the amount of the active compound in the blood over a period of time has to be within plus-or-minus $20 \%$, in comparison to the innovator drug [9]. The FDA states on its website in answer to the question "Are generic drugs as effective as brand-name drugs?": "Yes, a generic drug is the same as a brand-name drug in dosage, safety, strength, quality, the way it works, the way it is taken, and the way it should be used" [2]. A similar practice concerning approval of generic drugs has been adopted in the states of the European Union [7,11].

Despite the political promotion of the use of generic drugs and the establishment of a legal framework, numerous data exist which describe complications related to this medication class [12-15]. Additionally to differences between the bioequivalence of innovator products and generics, major concerns associated with abrupt discontinuation of the former, and a switch to generics had been reported [15-17]. Quality issues have also been raised in the USA by the so-called "four-dollar" generics, making low-cost medication widely accessible through major pharmacy chains [18]. These developments have contributed to doubts about the efficacy and quality of generics, especially in the view of older physicians and pharmacists [19].

Following public consultations on proposals to implement generic substitution in primary care, the UK Department of Health recently decided against introducing any such law [20]. One of the key issues in the decision not to pursue a legal requirement was "the perception strongly held by consultation respondents that generic substitution posed a threat to patient safety" [20]. Although not stated, it is likely that these safety concerns were expressed by the medical profession, rather than by health economists.

Previously published data by our group as well as novel data in this article, contradict a global uncritical approval of generic drugs. Whilst no view will be expressed on risks associated with oral medication with generics, we will focus exclusively on the intravenous administration route in severely ill patients [21]. Former work from our laboratory

*Corresponding author: Kirkpatrick CJ, Institute of Pathology, University Medica Center of the Johannes Gutenberg University, Langenbeckstrasse 1, D-55101 Mainz, Germany, E-mail: kirkpatrick@ukmainz.de

Received May 04, 2013; Accepted May 15, 2013; Published May 20, 2013

Citation: Kirkpatrick CJ, Rangoonwala R, Reshetnykov M, Barbeck M, Ghanaat S (2013) Non-Equivalence of Antibiotic Generic Drugs and Risk for Intensive Care Patients. Pharmaceut Reg Affairs 2: 109. doi:10.4172/2167-7689.1000109

Copyright: (c) 2013 Kirkpatrick CJ, et al. This is an open-access article distributed under the terms of the Creative Commons Attribution License, which permits unrestricted use, distribution, and reproduction in any medium, provided the original author and source are credited. 
involved a detailed study of generics of the antibiotic cefotaxime, in which the innovator product, Claforan ${ }^{\circledR}$, was compared with some of its generics [21]. This in vivo study was designed to test the possible functional significance of particulate contaminants, and aimed at simulating the state of the microcirculation in a typical patient in the intensive care unit (ICU), that is, generally with some degree of multiple organ dysfunction syndrome (MODS), in the form of microcirculatory dysfunction [22-25]. This was simulated using the rodent "dorsal skinfold chamber technique", which permits direct observation of the microcirculation in an awake animal for a period of up to 21 days, with quantification of important physiological parameters of the microcirculation [26]. Microcirculatory dysfunction was induced by ischemia and reperfusion (I/R) injury, and the state monitored by the functional capillary density (FCD), that is the percentage of the capillary system in the observed microcirculation being actively perfused, as quantitatively determined from images taken randomly from video microscopy. The study using cefotaxime generics demonstrated in a membrane filter technique that many generics were contaminated by foreign particulate matter, and that intravenous injection of these particles in the rodent model caused further shut-down of the compromised microcirculation [21]. Detailed histological analysis of the skin window tissue revealed particulates in the lumen of capillary branches.

In the present study, a different antibiotic, imipenem in the form of the innovator product, and a number of its worldwide generics, were investigated both by the membrane filter method to visualize particulate contaminants, and the dorsal skinfold chamber technique, but using in the latter a mouse model instead of the hamster. The data demonstrate that this imipenem investigation yields similar results to the cefotaxime data, with respect to the deleterious effect on tissue perfusion. However, in contrast to the earlier study, in which the particulates were detected in the tissue with impaired perfusion, the present study showed marked microcirculatory shutdown, without particulate matter being found in the affected region. This would suggest functional disturbances beyond the simple mechanisms of mechanical blockage of the microcirculation, and will require more detailed investigation.

\section{Materials and Methods}

\section{Source of innovator product and generics}

The imipenem innovator product, “Tienam ${ }^{\circledR}$ " was kindly provided by Merck, Sharp and Dohme (MSD, USA). The generics Prepenem ${ }^{\circledR}$, Tilam $^{\circledR}$, Yungjin ${ }^{\circledR}$ and Zilonem ${ }^{\circledR}$ were obtained from Korea, Taiwan, Thailand and India, respectively. All samples were in powder form in sterile vials as for clinical use. Each vial contained $1 \mathrm{~g}$ of sterile powder of each of the above-mentioned antibiotics.

\section{In vivo study}

Animals: The animal experiments were performed after being approved by the Committee on the Use of Live Animals in Teaching and Research, Rhineland-Palatinate, Germany. A total of 24 female CD-1 mice (6- to 8-week old, 20-25 g body weight, Charles River Laboratories, Sulzfeld, Germany) were randomly divided into five experimental and one control group $(n=9)$. The animals were housed one per cage, kept with water ad libitum, an artificial light-dark regime, and fed with regular mouse pellets (Laboratory Rodent Chow, Altromin, Germany), at the Laboratory Animal Unit of the Institute of Pathology, Johannes Gutenberg University Mainz, Germany.

Particulate separation for in vivo application: The particulate matter separation for the in vivo application was performed according to the described method of Lehr et al. [21]. In brief, $100 \mathrm{ml}$ of sterile saline $(0.9 \%$; Braun, Melsungen, Germany) were injected into the original vials, in order to dissolve the powder within each vial. A filter with a pore size of $0.2 \mu \mathrm{m}$ (Supor ${ }^{\circledR} 200$ PES Membrane Disc Filter, Pall Life Science, USA), was used in order to filter the solution. The residuals on the filter membranes were then resuspended in $10 \mathrm{ml}$ of the abovementioned saline. Subsequently, a centrifugation process of $15 \mathrm{~min}$ at $4500 \mathrm{rpm}$ was performed. The acquired pellets were resuspended in $100 \mu \mathrm{l}$ of normal saline, and injected intravenously as a bolus into the animals via the in-dwelling catheter.

Skinfold chamber animal model, catheter implantation and experimental set up: For intravital fluorescence microscopy, the dorsal skinfold chamber preparation as well as the application of an indwelling catheter in the jugular vein in the CD-1 mouse was performed according to the previously described method $[21,22,26]$. The application of this model permits the intravital microscopic visualization and quantification of the nutritional capillary perfusion in finely striated skin muscle $[21,22,26]$. An image of the skinfold chamber set up is given in figure 1 . The study was initiated after a time period of up to 3 days, in which inflammation related to operation was excluded. In each mouse, 10 identical microvascular regions of interest per chamber, each containing several parallel capillaries in the foreground, and one characteristic draining venule for orientation purposes were studied, visualized and recorded using intravital fluorescence microscopy. These same regions of interest were evaluated at baseline, after four hours of ischemia, and after two hours of reperfusion (post-ischemic value), and 10 minutes after injection of the antibiotic particulate solutions.

Immediately before the microscopical studies, fluorescein isothiocyanate-conjugated macromolecular dextran (FITC-dextran, Mr 150,000, $5 \mathrm{mg}$ in $100 \mu \mathrm{l}$ of saline; Sigma, St. Louis, MO) was injected intravenously, in order to visualize the plasma column. The pressure induced an ischemia of four hours, and was performed by gently pressing the muscle against the coverslip with a silicone pad and an adjustable screw, just sufficient to empty the blood vessels. For each experimental group, the particulate matter from the antibiotic solutions in $100 \mu \mathrm{l}$ of normal saline was injected intravenously via the implanted catheter. The animals of the control group received only $100 \mu \mathrm{l}$ of normal saline solution. All experiments were performed in a double-blinded fashion.

Image analysis: Image analysis was performed according to a previously described method $[21,22,26]$. The region of interest within

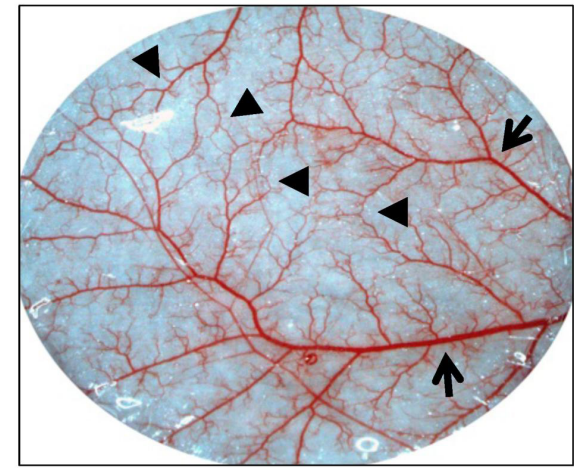

Figure 1: Macroscopic and microscopic images of the skinfold chambe model. (A) shows a macroscopic overview of the area of a skinfold chamber after ischemia and reperfusion. Note the major vessels (arrows) within the subcutaneous tissue that pass into the capillaries (arrow heads), which are subsequently microscopically assessed (25X magnification). 
the striated muscle microcirculation was visualized and recorded at each study time point at $100 \mathrm{X}$ magnification by using a fluorescent microscope, with a $100 \mathrm{~W}$ mercury lamp (ECLIPSE 80i microscope, Nikon, Tokyo, Japan), equipped with standard blue/green/red filters, in addition to a bright field source (Figure 2). Functional capillary density (FCD) was quantified using the image analysis system, NIS-Elements BR 3.0 (Nikon, Tokyo, Japan). Only capillaries that were perfused with red blood cells were used for assessment of the parameter FCD (Figure 2) $[21,22,26]$. The applied technique of quantifying functional capillary density enables reproducible results to be acquired, and is associated with a low interobserver variability [21].

Tissue preparation and histology: At the end of each study, the animals were euthanized by an overdose of ketamine and xylazine. For the purpose of characterization of the effects of particulate matter on the microcirculation, the tissue and organs, i.e. the tissue of the skinfold chamber, as well as the heart, lung, liver, kidney and spleen of the animals, were explanted and fixed in $4 \%$ buffered formalin for $24 \mathrm{~h}$ for further histological preparation. After dehydration in a series of graded alcohols, followed by xylene treatment, paraffin embedding was performed. For all tissue samples, serial sections at an interval of 50 $\mu \mathrm{m}$ were made. From each interval, two consecutive 3-4 $\mu \mathrm{m}$ thick slices were made and stained with Mayer's haematoxylin and eosin (H\&E)

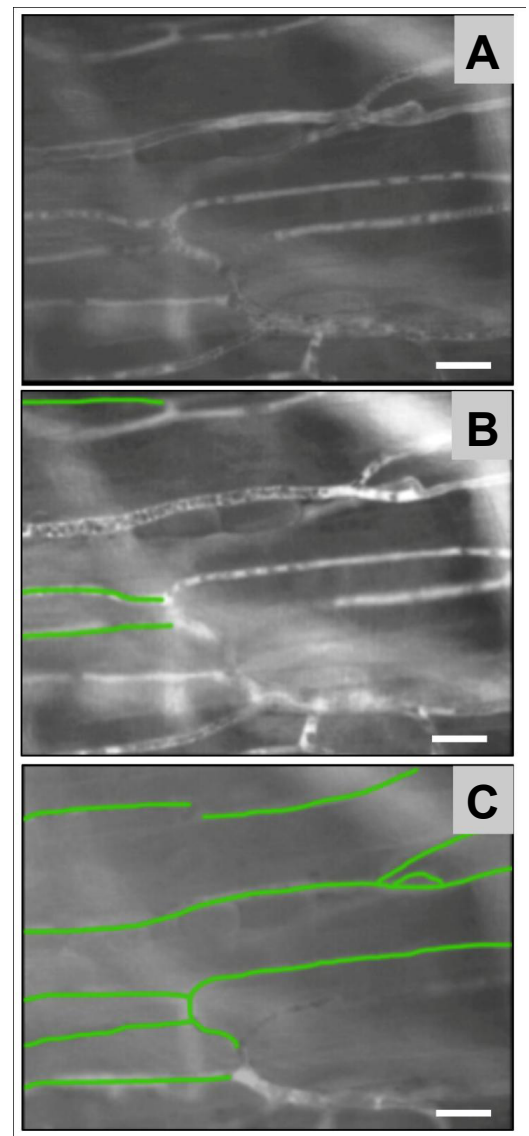

Figure 2: Representative images of capillaries within the striated panniculus carnosus muscle in a skinfold chamber to demonstrate the FCD after treatment by Tilam ${ }^{\circledR}$. Contrast enhancement was achieved by intravenous injection of FITC-labelled macromolecular dextran (FITC-dextran). The blocked capillaries are manually marked with green color. $(A)$ shows the state of vascularization before ischemia and reperfusion, ("baseline"). (B) shows the state of perfusion of the capillaries after ischemia and reperfusion while $(C)$ shows the same capillaries after particle injection $(200 x$ magnification, scale bars $=10 \mu \mathrm{m})$. and Giemsa for further histopathological examination (Figure 1). These sections were examined by two independent investigators for any effect of particle contamination. The investigations were conducted using a Nikon ECLIPSE 80i microscope (Nikon, Japan). Microphotographs were taken using a Nikon DS-Fil digital camera and a digital sight control unit (Nikon, Japan).

Statistical analysis: Quantitative data are presented as mean \pm standard deviation, and an analysis of variance (ANOVA) was carried out. Differences were considered significant if $\mathrm{P}$-values were less than $0.05\left({ }^{*} \mathrm{P}<0.05\right)$, and highly significant if $\mathrm{P}$-values were less than 0.01 or $0.001\left({ }^{\star *} \mathrm{P}<0.01{ }^{* * *} \mathrm{P}<0.001\right) . \mathrm{IBM}^{\circledR}$ SPSS $^{\circledR}$ Statistics 18 (SPSS Inc., an IBM Company, USA) was used for all calculations. GraphPad Prism 5.0d software (GraphPad Software Inc., La Jolla, USA) was used for plotting graphs.

\section{Particulate separation for particle size characterization}

The particulate matter separation for particle size characterization was performed according to the described method of Kirkpatrick and Rangoonwala [27]. In brief, demineralized particle-free water (DPFW) was prepared using a Super-Q Plus Ultra Purification System (Millipore, USA). Subsequently, the purity of the demineralised water was verified with the aid of a membrane filter (MF-Millipore ${ }^{\mathrm{tm}}$ Membrane Filters, $25 \mathrm{~mm}$ filter diameter, $0.8 \mu \mathrm{m}$ pore size Millipore, USA). The filters were evaluated and documented using an Olympus SZX12 stereomicroscope (Olympus, Japan). In a next step, a filtration apparatus was used for membrane filtration of the antibiotic vials based on a filtration funnel (Advantec, Ireland), and a vacuum tube connected to an evacuation system, in combination with cellulose membrane filters (MF-Millipore ${ }^{\text {Tw }}$ Membrane Filters, $25 \mathrm{~mm}$ filter diameter, 0.8 $\mu \mathrm{m}$ pore size, Millipore, USA). Furthermore, this system consisted of a vacuum pump (membrane pump with remaining pressure of $30 \mathrm{mbar}$ ), a collecting vessel and a tubing system.

For visualization of particulate matter contamination, the contents of one $500 \mathrm{mg}$ vial of the antibiotics were dissolved in $100 \mathrm{ml}$ DPFW. The dissolved solution of 3 vials was filtered under less than 500 mbar vacuum through the membrane filter. The whole procedure was performed under clean room conditions with minimized particulate burden (laminar flow bench). Following this, the membrane filters were fixed in sealable particle-free containers (Petri dishes, PALL, Germany). Filters were viewed under an Olympus SZX 12 stereomicroscope (Olympus, Japan), and documented by Hitachi HV-C 20M video camera (Hitachi, Japan) that was connected to a combined computer system. Using the software Analysis SIS, Version 3.1 (Olympus, Toyko, Japan), the microscope video prints could be viewed on the monitor and the data stored on the hard disk. For each product 3 filters were prepared.

\section{Results}

\section{Drug-induced impairment of the microcirculation}

Intravital microscopy in the mouse skin window technique was used to test the effects of injecting the various drug groups into a microcirculation made dysfunctional, using ischaemia/reperfusion (I/R) injury to simulate the state of organ perfusion of intensive care patients. The administered imipenem groups were tested in a blinded fashion, i.e. they were known to the experimental team only as a code, which was revealed after data collection. Figure 3 shows that prior to injection of the drug, the functional capillary density (FCD) of the various generic or innovator product groups (B to F) after I/R injury showed no statistically significant differences from the control group 

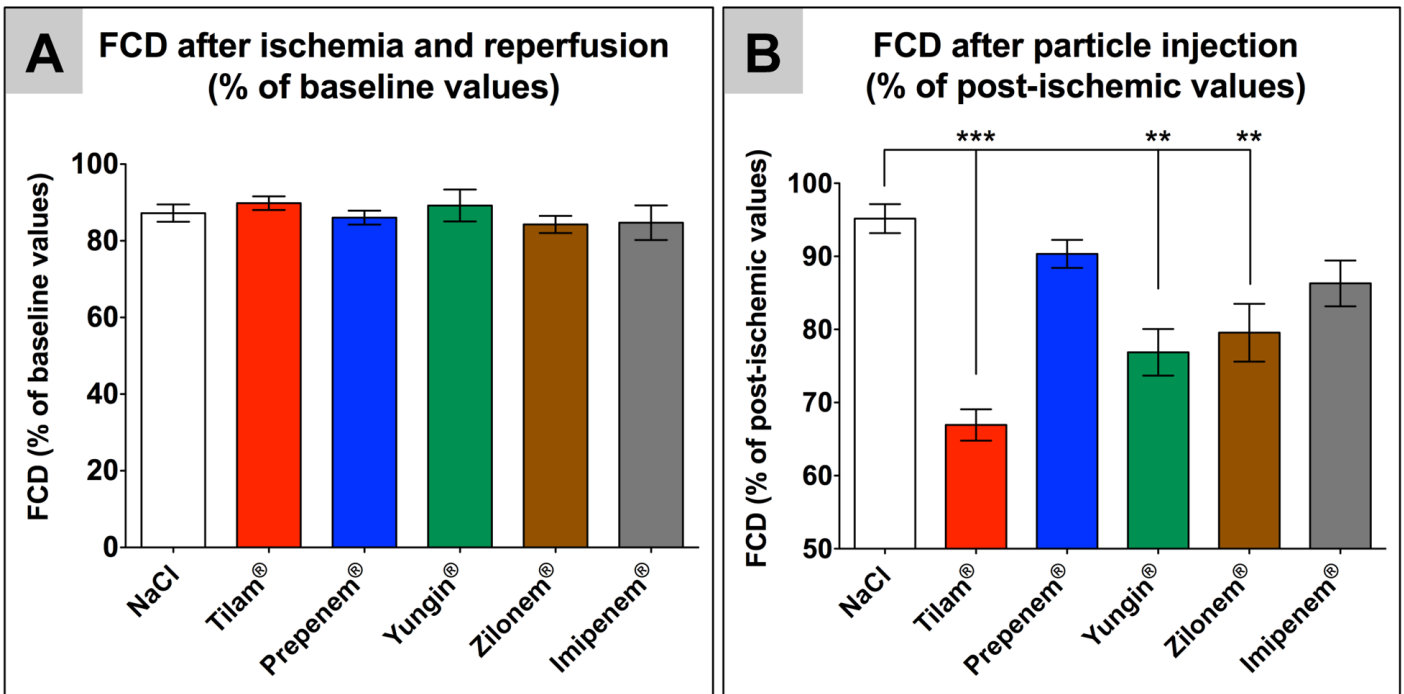

Figure 3: The graphical illustration of the measured Functional Capillary Density (FCD) within the muscle tissue of the skinfold chamber after (A) ischemia and reperfusion, and after $(B)$ antibiotic particle injection. Values are given as mean \pm standard deviation of the mean, and statistical significance was tested for each drug group against the control $\left({ }^{* *} \mathrm{P}<0.01 ;{ }^{* * *} \mathrm{P}<0.001\right)$.

(A). All were approximately $85 \%$ of the baseline value (100\%), the latter representing the measured FCD prior to microcirculatory damage.

Measurement of FCD following drug injection revealed marked differences between the various drug groups and the control. Thus, figure $3 \mathrm{~B}$ indicates that two groups, $\mathrm{C}$ and $\mathrm{F}$, did not differ from the control, in which saline only was injected. By contrast, the groups $\mathrm{D}$ and $\mathrm{E}(\mathrm{P}<0.01)$ and especially group $\mathrm{B}(\mathrm{P}<0.001)$ demonstrated a marked, statistically significant reduction in FCD, compared to the control. On breaking the code, it became evident that the drug groups non-significantly different from the control were the innovator product $\left(\mathrm{F}\right.$, Tienam $\left.^{\circledR}\right)$ and its generic Prepenem ${ }^{\circledR}(\mathrm{C})$. The generics Tilam ${ }^{\circledR}$, Yungjin ${ }^{\circledR}$ and Zilonem ${ }^{\circledR}$ (B, D and E resp.) were responsible for marked deleterious effects on microcirculatory perfusion, with FCD levels of $66.93 \pm 5.25 \%, 76.88 \pm 6.37 \%$ and $79.56 \pm 8.83 \%$ of the control $(\mathrm{A})$, respectively.

With the exception of the spleen, almost no particles were found within the microcirculatory bed of the skinfold chamber region. No particulate matter was observed in the heart, lungs, liver and kidneys of each animal in the study (data not shown).

\section{Physical characterization of the imipenem samples}

Using the separation technique described in the materials and methods section, it was demonstrated that the generic drugs used in this study were contaminated by a heterogeneous population of particulates, ranging from elongated fibres to smaller, dense and more spherical particles. It was not the aim of the study to perform detailed quantitative analysis on these filters, but principally to determine if there was an easily visible contamination of the generic drugs with particulates, and to compare this with the innovator product. The discoloration of some of the filters from the generics supports the presence of additional soluble contaminants, which are most probably leached out from the particulates. Further investigations are required to identify their molecular structure, but they could be readily identified by chromatographic or mass spectroscopic techniques.

Large numbers of particles of a size relevant for the microcirculation were indeed seen in those generics, which aggravated the compromised microcirculation in the animal model. Representative images of the drug samples after the membrane filter method are given in figure 4. In group $\mathrm{E}$ (Zilonem ${ }^{\circledR}$, Figure $4 \mathrm{E}$ ), numerous particles were between 1 and $3 \mu \mathrm{m}$, as well as in the filters of group B (Tilam ${ }^{\circledR}$, Figure $\left.4 \mathrm{~B}\right)$, which gave the greatest impairment of capillary perfusion. Interestingly, the generic $\mathrm{C}$ (Prepenem ${ }^{\circledR}$, Figure $4 \mathrm{C}$ ) which had predominantly elongated fibre-like particles, which ranged between $5-20 \mu \mathrm{m}$ that is of a size incapable of entering the capillaries, did not show any statistically significant decrease in the functional capillary density (FCD) in the animal study. Thus, there appears to be a good correlation between the size range of particulate contamination and the effects observed in the dorsal skinfold chamber. This does not mean, of course, that such fiber contamination is innocuous, as it appears that this larger size range of particle is shunted into other circulatory beds. In group D (Yungjin ${ }^{\circledR}$, Figure 4D), most particles were found between 1 and 5 $\mu \mathrm{m}$. In group $\mathrm{F}\left(\right.$ Tienam ${ }^{\circledR}$ Figure $4 \mathrm{~F}$ ), also round-shaped particles were found, which ranged between 1 and $3 \mu \mathrm{m}$. No particles were found within the group A, the control group without antibiotic (Figure 4A) In the generic groups, i.e. groups $\mathrm{B}, \mathrm{C}, \mathrm{D}$ and $\mathrm{E}$, the particle numbers were too numerous to count.

\section{Discussion}

The interest of this work for intensive care medicine derives from the fact that a typical patient on Intensive Care Unit (ICU) receives large volumes of fluid, as well as medication intravenously. Our working hypothesis was that particulate contaminants in the administered solutions could represent a health hazard for the patient by causing mechanical blockage, and/or endothelial activation in the microcirculation. This was the motivation for the development of a relevant functional model in an experimental animal. Our model was designed to simulate as closely as possible the state of the microcirculation in a typical intensive care patient. Numerous studies have shown that ICU patients with multiple organ dysfunction syndromes (MODS) have varying degrees of microcirculatory dysfunction, irrespective of whether they are post-traumatic, postinfection etc. [24]. 
Citation: Kirkpatrick CJ, Rangoonwala R, Reshetnykov M, Barbeck M, Ghanaati S (2013) Non-Equivalence of Antibiotic Generic Drugs and Risk for Intensive Care Patients. Pharmaceut Reg Affairs 2: 109. doi:10.4172/2167-7689.1000109
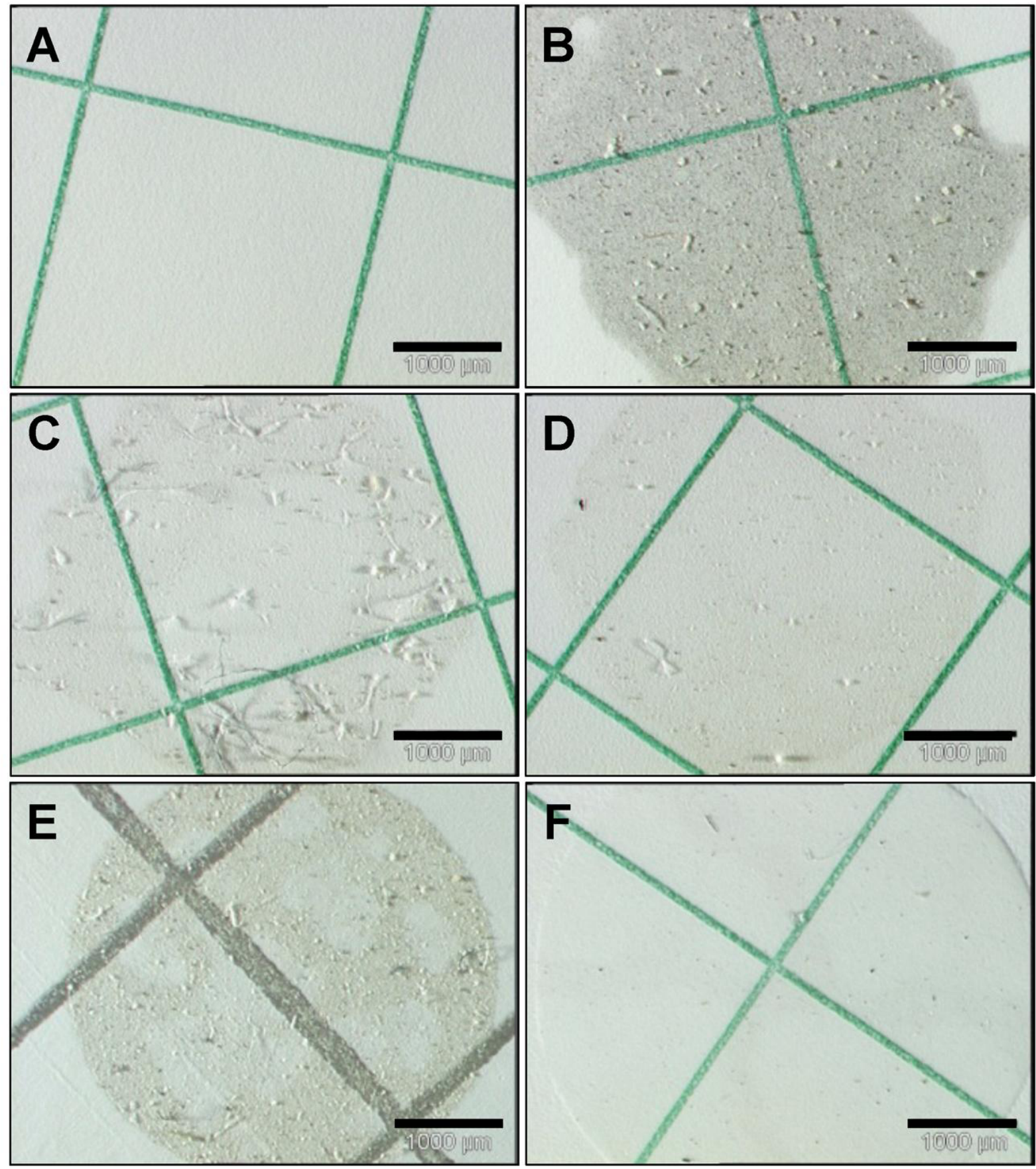

Figure 4: Representative images of the filters used for the filtration method to detect particulate matter contamination. Note the numerous particulates $(<5 \mu m)$ in the generics Tilam ${ }^{\circledast}(B)$, Yungjin ${ }^{\circledR}(D)$ and Zilonem ${ }^{\circledR}(E)$, while the generic Prepenem ${ }^{\circledR}(C)$ showed mostly elongated, fibre-like particles. The filters of the saline control group is free $(A)$ and the Tienam ${ }^{\circledR}$ group $(F)$, almost free of particulate contamination.

Using the membrane filter method, the results of this study reveal that many generics contain foreign particulate material, and this raises the pertinent question how such a state is possible in a regulatory environment. To identify the chemical composition of contaminating particles, additional studies are currently being performed on selected filters using scanning electron microscopy (SEM) and energy-dispersive analysis of X-rays (EDAX) as shown by Walpot et al. [28].

It is instructive to compare the demands made on companies bringing an innovative drug on to the market and those making its generic. The former must perform every step according to Good Manufacturing Practice (GMP) standards, i.e. there are safety checks at all involved stages. For approval, a generic must demonstrate so-called bioequivalence, which in the EMEA (European Medicines Agency) guideline of January 2010 is defined as follows: "Two medicinal products containing the same active substance are considered bioequivalent, if they are pharmaceutically equivalent or pharmaceutical alternatives and their bioavailabilities (rate and extent), after administration in the 
same molar dose lie within acceptable predefined limits. These limits are set to ensure comparable in vivo performance, i.e. similarity in terms of safety and efficacy" [29]. Whilst the present report concerns itself experimentally with particulate contamination, there is further evidence from the literature that generics also suffer from fluctuating dosage. Thus, for example, in a single-dose pharmacokinetic assessment (in healthy volunteers) of two amoxicillin generics in Italy, one was found to be not bioequivalent with the innovator product [30]. Even changing the salt form, for example, of the calcium channel blocker, amlodipine, has been shown to alter drug stability and the formation of impurities [31]. On plotting the mean plasma concentration against the time after dosage, the AUC (area under the concentration-time curve) can be calculated, and this, together with the maximum plasma concentration $\mathrm{C}_{\max }$, are the usual pharmacokinetic variables used to assess bioavailability. Although the tolerance range for bioequivalence is usually taken as between 80 and $125 \%$, studies by the FDA in the 1990's comparing innovator products and their generics indicated that the observed differences were less than 5\% [32,33]. Despite the fact that such historical data are very useful to study trends, they have no predictive value for any new generic appearing on the market. Moreover, there are patient groups such as epileptics for whom the therapeutic window for the drugs of choice is narrow, so that bioequivalence can scarcely be defined so broadly [34]. The tolerance, with respect to bioavailability, is also critical in severely ill patients requiring antimicrobial treatment, and the risks associated with underdosage of antibiotics are well described, such as the induction of bacterial resistance [35].

In vitro studies are also being used to compare the antimicrobial activity of an innovator product and its generics. Thus, Diaz et al. [36] made comparisons of vancomycin preparations and found similarity, for example, with respect to minimal inhibitory concentrations (MICs), minimal bactericidal concentrations (MBCs) and resistant mutants etc., concluding that this demonstrated pharmaceutical equivalence. By contrast, Vesga et al. [37] performed similar comparisons on vancomycin innovator product and its generics, but looked additionally at equivalence of efficacy in vivo. This latter group also demonstrated no differences in antibacterial effect in vitro, but reported that all generics which were tested failed to kill Staphylococcus aureus in a neutropenic mouse thigh infection model. Their conclusion was that "pharmaceutical equivalence does not imply therapeutic equivalence for vancomycin" [37]. Moreover, a recent publication from this group demonstrated in the same experimental model that a generic vancomycin favoured the development of resistance in a subpopulation of Staphylococcus aureus under the therapy [38]. It is evident that the only relevant equivalence for clinical practice is the therapeutic one.

Pharmacoeconomics is a field of endeavour which is gaining in importance, as health care depends on budget availability, the latter ultimately being determined by governmental policy at both national and local level. Cost minimization is an all-pervading principle, which has led to the almost axiomatic statement that generic drugs can and should be prescribed, as they are equivalent to brand-name medication except for their lower price.

ICU physicians are very aware of the fact that microbial infections need to be treated effectively to reduce mortality and keep costs to a minimum. Pittoni and Scatto [39] showed that in severely ill patients the major cost components come from mechanical ventilation and sepsis management, while Dasta et al. [40] calculated on the basis of data from 253 US hospitals that mean incremental costs of mechanical ventilation amount to > \$US $1.500,00$ per day. In a Norwegian University hospital setting, Flaatten and Kvale [41] determined average costs of an ICU day at $€ 2601,00$. More recently, for the South American continent, Sogayar et al. [42] evaluated the costs of ICU treatment of septic patients in Brazil, concluding that the median daily ICU cost per patient was $\$$ US 934,00 , but that this was even higher, namely \$US 1.094,00, for non-survivors. In a Canadian study on published and institutional data, Muscedere et al. [43] described an ICU bed as costing CAN dollars 2.396,00 per day. Of relevance for the present discussion is their calculation that each episode of ventilatorassociated pneumonia (VAP) extended the ICU stay on average by 4.3 days, which extrapolated to other countries could amount to additional costs, varying between \$US 4.000,00 and \$US 15.000,00. The medical and economic problems of VAP are also highlighted by Eagye et al. [44], who studied the economic impact of respiratory superinfection in patients being treated for VAP. This detailed study in 74 patients discharged between 2004 and 2005 showed that mean costs for the ICU stay differed by approximately $\$$ US $67.000,00$, if the patients being treated for VAP developed a superinfection (mainly P. aeruginosa, $S$. aureus, Klebsiella spp.). This extract from the literature makes it very clear that the economic burden on the health system is enormous, if ICU patients are ineffectively treated for bacterial infections. It is self-evident that this will be the case if patients are administered substandard medications, as seen by some generics studied in the present paper.

The data from our previous study on generic cefotaxims by Lehr et al. [21], and the data generated in this paper with imipenem generics clearly contradict the view that there is equivalence in quality between the originator products and their generics. There are practical conclusions to be drawn from the present study. It is evident that in vivo testing with a sophisticated model as presented here is not feasible for the numerous generic preparations used in contemporary medicine. However, for intensive care medicine, in which most medication is given intravenously, there is a strong case to be made for using a membrane filter technique and optical microscopy to check the quality of drugs to be administered to ICU patients. Indeed, this is a recommendation that is to be found in all three major pharmacopoeial texts for testing sub-visible particles (European Pharmacopoeia 2005, Japanese Pharmacopoeia 2006, United States Pharmacopeia 2007). Based on our studies, we have to assume that these recommendations are not being followed. Having a sub-visible particle testing facility in a hospital pharmacy with the possibility of serving a series of hospitals in a region would be an economically viable model. Our data indicate that the presence of a large number of small particle contaminants correlates with functional disturbance in the microcirculation. Thus, on this basis, such drugs could be removed from the hospital's purchasing list. Finally, it is an indictment of contemporary, profit-driven medicine that the end-user appears compelled, in the interests of the patient, to set up quality control monitoring in lieu of companies, which are legally and morally obliged to perform such studies, but obviously do not.

\section{Acknowledgement}

No author is involved in purchasing or drug prescription to patients. This research was supported in part by the State of Rhineland-Palatinate and in part by an MSD grant.

\section{References}

1. Duerden MG, Hughes DA (2010) Generic and therapeutic substitutions in the UK: are they a good thing? Br J Clin Pharmacol 70: 335-341.

2. U.S. Department of Health and Human Services (2011) Generic Drugs: Questions and Answers.

3. Frank RG (2007) The ongoing regulation of generic drugs. N Engl J Med 357 1993-1996. 
Citation: Kirkpatrick CJ, Rangoonwala R, Reshetnykov M, Barbeck M, Ghanaati S (2013) Non-Equivalence of Antibiotic Generic Drugs and Risk for Intensive Care Patients. Pharmaceut Reg Affairs 2: 109. doi:10.4172/2167-7689.1000109

Page 7 of 7

4. Lofgren H (2004) Generic drugs: International trends and policy developments in Australia. Aust Health Rev 27: 39-48.

5. Shragel L, Kanfer I (2009) Generic drug product development: International regulatory requirements for bioequivalence. (1st Edn.), Informa Healthcare.

6. Keenum AJ, Devoe JE, Chisolm DJ, Wallace LS (2012) Generic medications for you, but brand-name medications for me. Res Social Adm Pharm 8: 574 578.

7. Minghetti $P$ (1996) Regulatory status of medicinal products for human beings in the European Union. The role of generic products. Pharmacol Res 34: 3-7.

8. Sokal AM, Gerstenblith BA (2010) The Hatch-Waxman Act: Encouraging innovation and generic drug competition. Curr Top Med Chem 10: 1950-1959.

9. Mossinghoff GJ (1999) Overview of the Hatch-Waxman Act and its impact on the drug development process. Food Drug Law J 54: 187-194

10. U.S. Food and Drug Administration (2011) Abbreviated new drug application (ANDA): Generics. FDA, USA.

11. Frequently Asked Questions about Generic Medicines. European Generic Medicines Association, Belgium.

12. Heller FR, Dupont AG (2009) Generics: need for clinical concern? Acta Clin Belg 64: 415-422.

13. Kumet R, Gelenberg AJ (2005) The effectiveness of generic agents in psychopharmacologic treatment. Essent Psychopharmacol 6: 104-111.

14. Kalodiki E, Fareed J (2011) New and generic anticoagulants and biosimilars: safety considerations. Clin Appl Thromb Hemost 17: 136-139.

15. Genazzani AA, Pattarino $F$ (2008) Difficulties in the production of identical drug products from a pharmaceutical technology viewpoint. Drugs R D 9: 65-72.

16. Al-Jazairi AS, Bhareth S, Eqtefan IS, Al-Suwayeh SA (2008) Brand and generic medications: are they interchangeable? Ann Saudi Med 28: 33-41.

17. Wilner AN (2004) Therapeutic equivalency of generic antiepileptic drugs: results of a survey. Epilepsy Behav 5: 995-998.

18. Choudhry NK, Shrank WH (2010) Four-dollar generics--increased accessibility, impaired quality assurance. N Engl J Med 363: 1885-1887.

19. Shrank WH, Liberman JN, Fischer MA, Girdish C, Brennan TA, et al. (2011) Physician perceptions about generic drugs. Ann Pharmacother 45: 31-38.

20. Department of Health (2010) The proposals to implement 'Generic Substitution' in primary care, further to the Pharmaceutical Price Regulation Scheme (PPRS) 2009. Consultation document. DH, USA.

21. Lehr HA, Brunner J, Rangoonwala R, Kirkpatrick CJ (2002) Particulate matter contamination of intravenous antibiotics aggravates loss of functional capillary density in postischemic striated muscle. Am J Respir Crit Care Med 165: 514 520.

22. Ghanaati S, Webber MJ, Unger RE, Orth C, Hulvat JF, et al. (2009) Dynamic in vivo biocompatibility of angiogenic peptide amphiphile nanofibers. Biomaterials 30: 6202-6212.

23. Kirkpatrick CJ, Bittinger F, Klein CL, Hauptmann S, Klosterhalfen B (1996) The role of the microcirculation in multiple organ dysfunction syndrome (MODS): a review and perspective. Virchows Archiv 427: 461-476.

24. Lehr HA, Bittinger F, Kirkpatrick CJ (2000) Microcirculatory dysfunction in sepsis: a pathogenetic basis for therapy? J Pathol 190: 373-386.

25. Peters K, Unger RE, Brunner J, Kirkpatrick CJ (2003) The molecular basis of endothelial dysfunction in sepsis. Cardiovascular Res 60: 49-57.

26. Lehr HA, Leunig M, Menger MD, Nolte D, Messmer K (1993) Dorsal skinfold chamber technique for intravital microscopy in nude mice. Am J Pathol 143 1055-1062.

27. Kirkpatrick CJ, Rangoonwala R (2009) Originator antibiotic or generic in clinical practice. J Appl Ther Res 7: 52-57.
28. Walpot H, Franke RP, Burchard WG, Agternkamp C, Müller FG, et al. (1989) Particulate contamination of infusion solutions and drug additives within the scope of long-term intensive therapy. 1. Energy dispersion electron images in the scanning electron microscope-REM/EDX (in German). Anaesthesist 38 : 544-548.

29. European Medicines Agency (2010) Guideline on the investigation of bioequivalence. EMEA, London, UK.

30. Del Tacca M, Pasqualetti G, Di Paolo A, Virdis A, Massimetti G, et al. (2009) Lack of pharmacokinetic bioequivalence between generic and branded amoxicillin formulations. A post-marketing clinical study on healthy volunteers. Br J Clin Pharmacol 68: 34-42.

31. Meredith PA (2009) Potential concerns about generic substitution: Bioequivalence versus therapeutic equivalence of different amlodipine salt forms. Curr Med Res Opin 25: 2179-2189.

32. Henney JE (1999) Review of generic bioequivalence studies. JAMA 282: 1995

33. Bialer M, Midha KK (2010) Generic products of antiepileptic drugs: a perspective on bioequivalence and interchangeability. Epilepsia 51: 941-950.

34. Heaney DC, Sander JW (2007) Antiepileptic drugs: generic versus branded treatments. Lancet Neurol 6: 465-468.

35. Pea F, Viale P (2009) Bench-to-bedside review: Appropriate antibiotic therapy in severe sepsis and septic shock--does the dose matter? Crit Care 13: 214

36. Diaz JA, Silva E, Arias MJ, Garzón M (2011) Comparative in vitro study of the antimicrobial activities of different commercial antibiotic products of vancomycin. BMC Clin Pharmacol 11: 9.

37. Vesga O, Agudelo M, Salazar BE, Rodriguez CA, Zuluaga AF (2010) Generic vancomycin products fail in vivo despite being pharmaceutical equivalents of the innovator. Antimicrob Agents Chemother 54: 3271-3279.

38. Rodriguez CA, Agudelo M, Zuluaga AF, Vesga O (2012) Generic vancomycin enriches resistant subpopulation of Staphylococcus aureus after exposure in neutropenic mouse thigh infection model. Antimicrob Agents Chemother 56 243-247.

39. Pittoni GM, Scatto A (2009) Economics and outcome in the intensive care unit. Curr Opin Anaesthesiol 22: 232-236.

40. Dasta JF, McLaughlin TP, Mody SH, Piech CT (2005) Daily cost of an intensive care unit day: the contribution of mechanical ventilation. Crit Care Med 33 1266-1271.

41. Flaatten $\mathrm{H}$, Kvale $\mathrm{R}$ (2003) Cost of intensive care in a Norwegian University hospital 1997-1999. Crit Care 7: 72-78.

42. Sogayar AM, Machado FR, Rea-Neto A, Dornas A, Grion CM, et al. (2008) A multicentre, prospective study to evaluate costs of septic patients in Brazilian intensive care units. Pharmacoeconomics 26: 425-434.

43. Muscedere JG, Martin CM, Heyland DK (2008) The impact of ventilatorassociated pneumonia on the Canadian health care system. J Crit Care 23 5-10.

44. Eagye KJ, Nicolau DP, Kuti JL (2009) Impact of superinfection on hospita length of stay and costs in patients with ventilator-associated pneumonia. Semin Respir Crit Care Med 30: 116-123. 